\title{
Solar membrane distillation: a control perspective*
}

\author{
Juan D. Gil, Alba Ruiz-Aguirre, Lidia Roca, Guillermo Zaragoza and Manuel Berenguel, Senior \\ Member, IEEE
}

\begin{abstract}
This paper presents a preliminary architecture for controlling solar membrane distillation facilities. Membrane distillation (MD) is a desalination technology under investigation, without industrial applications and with only few pilot systems. There is a general lack of information on how these systems perform during real solar-powered operation and how distillate quality deteriorates under intermittent conditions. One of the few systems that have been fully described in literature is the MD-solar pilot plant in Plataforma Solar de Almería (PSA), Spain. This paper presents a first step towards an optimal automatic operation of this system through the definition of operation modes and basic control loops. A discussion of control schemes to be implemented in the near future is also included in this work.
\end{abstract}

Keywords: desalination, feedforward control, hybrid system, solar energy.

\section{INTRODUCTION}

Solar membrane distillation (SMD) is a technology under investigation for small-medium size water needs in places with good solar irradiance conditions [1-6]. The main advantages of this technology are [7,8]: i) low operation temperature $\left(60-90{ }^{\circ} \mathrm{C}\right)$, ii) low maintenance requirements and iii) it can be easily coupled with well-known reliable solar technologies. However, MD has not been implemented in industry, being MD membrane and module design, membrane pore wetting, flow rate control and uncertainty in energetic and economic costs the major barriers $[9,10]$.

$\mathrm{MD}$ is a thermally-driven separation process [4] produced in a porous hydrophobic membrane. Thanks to the vapour pressure difference between the two sides of the membrane, a flow of vapour molecules is established while non-volatile components are rejected. Recent research on SMD technologies are focused on evaluating, by means of experimental campaigns, different kinds of module designs and configurations $[7,8,11,12]$. Distillate production, specific thermal energy consumption and thermal efficiency are the most relevant parameters studied to evaluate the performance of a membrane module. To reach relevant conclusions with these studies, specific variables involved in the process (water temperatures of the cold and hot sources and feedwater flow rates) must be maintained in steady state

*Research supported by the project Controlcrop (P1O-TEP-6174) funded by the Andalusian Government and by projects DPI2014-56364-C2$1 / 2-R$ financed by the Spanish Ministry of Science and Innovation and EUERDF funds.

J. D. Gil and M. Berenguel are with the University of Almería, CIESOLceiA3, Spain, (e-mail jgv132@inlumine.ual.es ; beren@ual.es).

A. Ruiz, L.Roca and G. Zaragoza are with the Plataforma Solar de Almería - CIEMAT, CIESOL, Tabernas, Almería, Spain, (e-mail: alba.ruiz@psa.es, lidia.roca@psa.es, guillermo.zaragoza@psa.es). conditions. Nevertheless, due to the variability of irradiance, temperature variables are difficult to be controlled even by skilled operators. This fact can lead to undesirable extension of the experimental campaigns or the use of non-renewable energy sources to accomplish the operation requirements.

There are a few works dealing with control of SMD processes. In [9], an overview of basic modeling approaches is carried out, together with a description of operating variables affecting MD process and rate controlling steps to be carried out in different configurations. Dynamic modeling and optimization in membrane distillation systems is presented in [13], where a dynamic model based on a 2D advection-diffusion equation is presented. A visual library for Matlab environment was presented in [14] for design and simulation of different types of solar desalination systems. In [15] a mathematical model is developed for simulating a solar vacuum membrane distillation unit, aimed at determining its daily productivity. A dynamic simulation model for a solar driven membrane distillation system was developed in [16,17] using Aspen Custom Modeler based on heat and mass transfer. The effects of adopting different objective functions, solar radiation conditions, thermal storage tank configurations, as well as flowrates of the membrane distillation module and the thermal storage tank on the optimized performance are reported. In [18], a double loop optimization problem was formulated to solve the highly nonlinear equations with unknown outlet and membrane surface conditions to implement a simulation procedure. An additional outer loop was also implemented to accommodate the dynamic condition of a real lab-scale membrane distillation unit. A pseudo-real-time dynamic optimization was performed to minimize the energy expenses. Convex optimization was used in [19] within the framework of membrane distillation bio-reactors to optimize operational setpoints in a hierarchical control approach.

The first work addressing automatic control was [20], where a model of a MD unit was developed and two feedback temperature control loops were tested in simulation. In $[16,17]$ a control system using conventional PI and on/off controllers is proposed for temperature control purposes. The main control approach at present is [21], where a neural network-based optimizing control system for a seawaterdesalination solar-powered membrane distillation unit is presented. A neural network model of the system has been trained and tested using experimental data. This model has been used for the analysis of the process performance (distillate production) under various operating conditions (feed flow rate, solar radiation and cold feed temperature). A control system has been developed to optimize distillate production under variable operating conditions. Feedforward controllers (FF) following the ideas in [22-25] were implemented. 
This paper is focused on the study and implementation of a control architecture for an experimental SMD facility in order to improve the system operation and reduce the use of nonrenewable energy. Due to the hybrid nature of the pilot plant, operating modes are firstly identified. Basic control schemes are proposed and particularized for each subsystem and operating mode. For one of those operating modes (the nominal one), preliminary control results are compared with a typical operation procedure in manual mode.

\section{SYSTEM DESCRIPTION}

\section{A. System description}

The test facility (see Fig. 1) consists of a desalination unit (MD module) connected to solar field through a heat exchanger and a distribution system which enables simultaneous connection of several membrane units. The required thermal energy to achieve the temperature difference inside the module is provided by a solar thermal field divided into two files of Flat-Plate Collectors (Solaris CP1 Nova by Solaris, Spain), each one consisting of five collectors. Solaris CP1 is a flat plate collector with a total dimension of $2082 \times 1082 \times 85 \mathrm{~mm}$. The absorber surface is $2 \mathrm{~m}^{2}$ and is made of aluminum with high efficiency selective coating of mirotherm. The exposed face is a tempered glass of $3.2 \mathrm{~mm}$ thickness with low iron content, while the others sides are thermally insulated with mineral wool of $25 \mathrm{~mm}$ thickness. The nominal thermal power of this solar field is 7 $\mathrm{KW}$ th for a temperature of $90{ }^{\circ} \mathrm{C}$ approximately, using as thermal fluid demineralized water with antifreeze (GEO FLUID 100, Saleplas) in a proportion of 22:100 (GEO FLUID:water). The solar loop has a thermal storage tank (1500 1) that can be used to work in steady conditions or when the weather conditions are not favorable. This tank includes two electrical resistance heaters that can be used for energy support when the thermal power delivered by the solar field is not enough to reach the desired operating conditions in the MD system. When the tank is cold, the module of MD is coupled directly with the solar field, which temperature is controlled by changing the fluid mass flow rate using the pump B1. Moreover, the field outlet is equipped with an air-cooler to control the temperature excess. Centrifugal stainless steel pump (WILO-Stratos 25/1-6 CAN PN 10), Electromagnetic flow meters (Promag $50 \mathrm{P} 15$ by Endress + Hauser), rotary drive with Sauter universal technology for ball valve (AKM 115S), pressure transmitters (S10 absolute by WIKA) and resistance thermometers with standard head IP67 equipped with thermowell were employed. A pyranometer (CM6B by Kipp + Zonen) was used to measure the global solar radiation on titled angle $\left(35^{\circ}\right)$. A SCADA system was implemented to record all the measured variables. All the temperatures, flow rates and pressures are monitored and controlled by a SCADA (Supervisory Control And Data Acquisition) connected through a PLC (Programmable Logic Controller). Fig. 2 shows a photo of the solar facility at PSA.

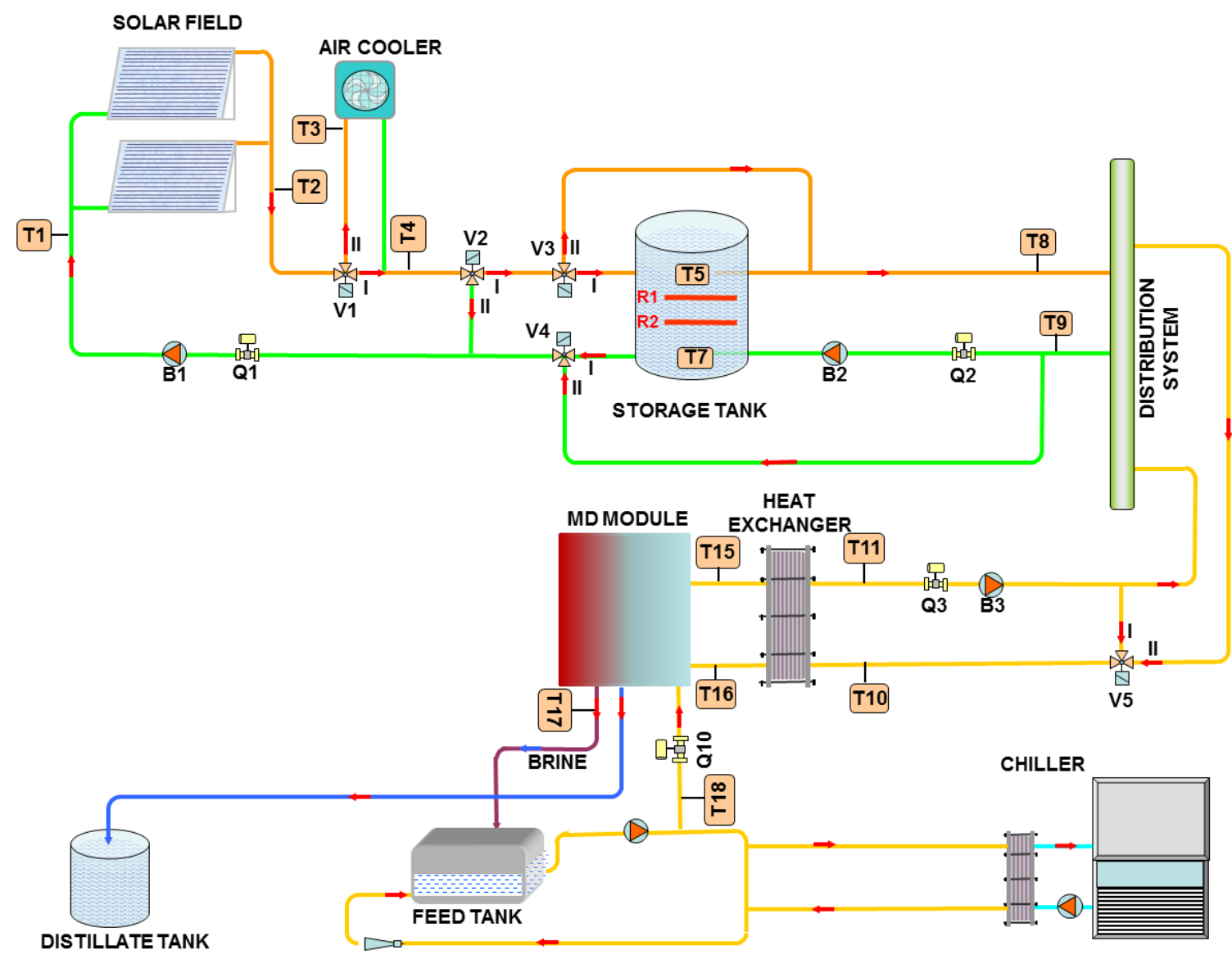

Figure 1. Schematic diagram of the solar facility at PSA 


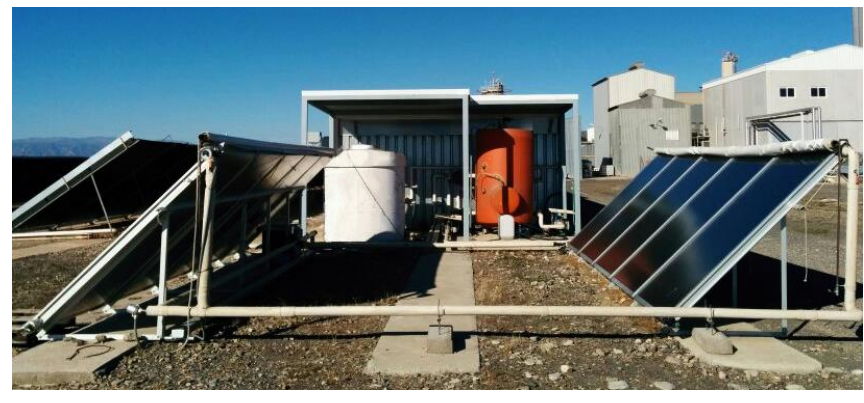

Figure 2. Solar facility at PSA.

As has been pointed out, membrane distillation (MD) is a thermally driven filtration process that can use renewable energy or low grade waste heat. The driving force is the trans-membrane vapour pressure difference, which is usually established by a temperature difference on both sides of the membrane [11]. The vapour flows through the micro pores of the hydrophobic membrane, while the aqueous solution is rejected by the hydrophobic behavior of the membranes as long as the liquid entry pressure of the pores is not exceeded. The operation of this MD system has been already described in $[11,26]$. It is worth mentioning that the salinity is kept constant performing at batch mode, returning the brine and the distillate to the feed tank. A compressor chiller is used to keep the feed temperature constant. Materials of the modules, mainly the membrane, impose a limitation in the maximum temperature reached inside the module (about 80 ${ }^{\circ} \mathrm{C}$ ). On the other hand, temperatures lower than $60^{\circ} \mathrm{C}$ result in a very low production. So, the temperatures studied varied from $60^{\circ} \mathrm{C}$ to $80^{\circ} \mathrm{C}$. The feed flow rate to the module ranged from $400 \mathrm{l} / \mathrm{h}$ to $600 \mathrm{l} / \mathrm{h}$.

\section{B. Operating modes}

The distillate facility can be run in several operating modes. Each mode is defined from valves positions and pumps, electric resistance heaters and air cooler states. 13 modes have been identified to operate efficiently the system and to reach the main control objective, to control the temperature and the water flow rate at the inlet of the MD system. Table I summarizes these modes, where valves positions (V) are defined according to Fig. 1 and pumps (B), electric resistance heaters $(\mathrm{R})$ and air cooler $(\mathrm{C})$ states are defined with values $0-1$ if the actuator is turned off or on, respectively.

TABLE I. FACILITY OPERATING MODES

\begin{tabular}{|l|c|c|c|c|c|c|c|c|c|}
\hline Mode & V1 & V2 & $\mathbf{V 3}^{\text {a }}$ & V5 & $\mathbf{B 1}$ & $\mathbf{B 2}$ & $\mathbf{B 3}$ & $\mathbf{R}^{\mathrm{b}}$ & $\mathbf{C}$ \\
\hline 1. Solar field & I & II & - & - & 1 & 0 & 0 & 0 & 0 \\
\hline $\begin{array}{l}\text { 2. Solar field \& } \\
\text { electric heaters }\end{array}$ & I & II & - & - & 1 & 0 & 0 & 1 & 0 \\
\hline 3. Solar tank load & I & I & I & - & 1 & 0 & 0 & 0 & 0 \\
\hline $\begin{array}{l}\text { 4. Solar \& electric } \\
\text { heaters tank load }\end{array}$ & I & I & I & - & 1 & 0 & 0 & 1 & 0 \\
\hline $\begin{array}{l}\text { 5. Solar field \& } \\
\text { tank unload }\end{array}$ & I & II & - & I $^{\mathrm{e}}$ & 1 & 1 & 1 & 0 & 0 \\
\hline $\begin{array}{l}\text { 6. Solar field, } \\
\text { electric heaters \& } \\
\text { tank unload }\end{array}$ & I & II & - & $\mathrm{I}^{\mathrm{e}}$ & 1 & 1 & 1 & 1 & 0 \\
\hline $\begin{array}{l}\text { 7. Solar tank load } \\
\text { \& unload }\end{array}$ & I & I & I & $\mathrm{I}^{\mathrm{e}}$ & 1 & 1 & 1 & 0 & 0 \\
\hline $\begin{array}{l}\text { 8. Solar and } \\
\text { electric heaters } \\
\text { tank load \& } \\
\text { unload }\end{array}$ & I & I & I & $\mathrm{I}^{\mathrm{e}}$ & 1 & 1 & 1 & 1 & 0 \\
\hline
\end{tabular}

\begin{tabular}{|l|c|c|c|c|c|c|c|c|c|}
\hline Mode & V1 & V2 & $\mathbf{V 3}^{\mathbf{a}}$ & V5 & $\mathbf{B 1}$ & $\mathbf{B 2}$ & $\mathbf{B 3}$ & $\mathbf{R}^{\mathbf{b}}$ & $\mathbf{C}$ \\
\hline $\begin{array}{l}\text { 9. Direct } \\
\text { connection }\end{array}$ & I & I & II & II & 1 & 0 & 1 & 0 & 0 \\
\hline $\begin{array}{l}\text { 10. Direct } \\
\text { connection \& } \\
\text { electric heaters }\end{array}$ & I & I & II & II & 1 & 0 & 1 & 1 & 0 \\
\hline 11. Tank unload & - & - & - & I $^{\mathrm{e}}$ & 0 & 1 & 1 & 0 & 0 \\
\hline $\begin{array}{l}\text { 12. Electric } \\
\text { heaters \& tank } \\
\text { unload }\end{array}$ & - & - & - & I $^{\mathrm{e}}$ & 0 & 1 & 1 & 1 & 0 \\
\hline $\begin{array}{l}\text { 13. Direct } \\
\text { connection \& air } \\
\text { cooler }\end{array}$ & II & I & II & II & 1 & 0 & 1 & 0 & 1 \\
\hline $\begin{array}{l}\text { 14. Partial direct } \\
\text { connection }^{\mathrm{d}}\end{array}$ & I & I & II & II & 1 & 1 & 1 & 0 & 0 \\
\hline
\end{tabular}

a. V4 position is the same as V3.

b. To simplify, it is considered that $\mathrm{R} 1$ and $\mathrm{R} 2$ have the same state.

c. Valve aperture in the range $[0-100] \%$.

d. This mode is only valid under the following conditions: high outlet temperature of the solar field (saturated flow); low values in B3 (T10 cannot be regulated with V5, that must be fully open; high temperature in the tank to achieve the desired temperature (with $\mathrm{Q} 2 \geq \mathrm{Q} 3$ to avoid cold water in the distribution system returning to the MD system). This mode makes sense to avoid using the aero, but still has to be studied.

e. Valve aperture in the range $[50,80] \%$.

- Mode 1. This mode is used in order to increase the temperature quickly, with MD module stopped.

- Mode 2. In this mode, fluid is recirculated through the solar field, at the same time that tank temperature is increased with the resistors (with MD module stopped).

- Mode 3. Fluid is recirculated through the tank until reaching a desire temperature to start the operation.

- Mode 4. Same as mode 3 using resistors to increase the temperature more quickly.

- Mode 5. MD module is operated with the tank, while the fluid is recirculated in the solar field until reaching the tank temperature.

- Mode 6. Same as mode 5 using resistors to keep or to increase de tank temperature.

- Mode 7. The thermal energy to the MD module comes from the tank (fed by the solar field).

- Mode 8. Same as mode 7 also using resistors.

- Mode 9. The thermal energy to the MD module comes directly from the solar field.

- Mode 10. MD module is operated with the solar field, while tank temperature is increased with the resistors.

- Mode 11. MD module is fed as in mode 5, but fluid is not recirculated trough the solar field.

- Mode 12. MD module is fed as in mode 6, but fluid is not recirculated through the solar field.

- Mode 13. MD module is fed as in mode 9, but air cooler is used in order to decrease the temperature when the flow rate in the solar field is saturated to the maximum.

- Mode 14. MD module is partly operated with the field and the tank.

\section{CONTROL SCHEMES FOR MODE 13}

As first step, the following control objectives and schemes have been identified and proposed: 
Solar field. A cascade controller with a FF term will be in charge of controlling the outlet temperature of the solar field, $\mathrm{T} 2$, to track the desired setpoint, $\mathrm{T}_{\mathrm{raf}}$. Fig. 3 shows the proposed scheme and related nomenclature is explained in Table II. The slave control loop provides the desired flow rate by acting on the B1 pump speed (frequency percentage applied to the variable frequency drive $\mathrm{f}_{\mathrm{B} 1}$ ). In the cascade outer loop, another PI controller chooses the required water flow rate to control the desired solar field temperature. The feedback loop is combined with a parallel FF controller to compensate for irradiance (I) and inlet (T1) and ambient temperatures $\left(T_{a}\right)$ disturbances, providing the operating point of the plant depending on the operating conditions. This scheme is typical in solar plants with distributed collectors [22]. This static FF is designed supposing that outlet solar field temperature (T2) may be modeled by considering the behavior of a hypothetical equivalent absorber tube with the same behavior as the whole solar field [25]:

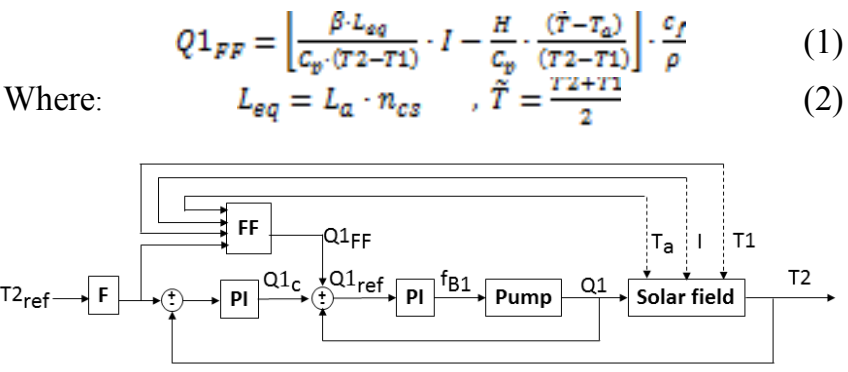

Figure 3. Solar-field temperature control.

A filter, F, has been included to add a degree of freedom and improve the setpoint response.

Air cooler. The objective of this control loop is to achieve a desired temperature T4 when the solar field control has oscillations due to transients caused by disturbances or the temperature is higher than desired (due to flow saturation). In order to save energy, a kind of split range controller should be used acting on both valve V1 aperture, $v_{1}$, and air cooler speed (frequency percentage), $\mathrm{f}_{\mathrm{ac}}$, (MISO system) using a PI controller (Fig. 4).

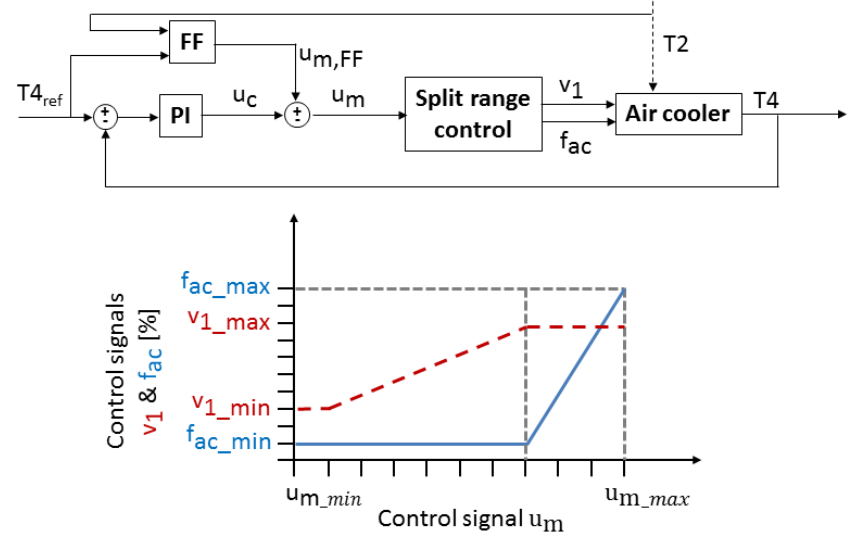

Figure 4. Air cooler control scheme.

$\mathrm{f}_{\mathrm{ac}}$ will vary from the lowest value when operating point changes are required, that is, when valve $v_{\mathrm{V} 1}$ value is reaching saturation. In this case, split-range control is used to define a fixed relationship between the global control signal provided by the PI controller, $\mathrm{u}_{\mathrm{m}}$, and the available manipulated variables: $v_{1}$ and $f_{a c}$. This relationship is estimated based on the combined influence of each manipulated variable in temperature T4 in steady state (temperature gradient), which determines when the air cooler is changed from its minimum value $\mathrm{f}_{\mathrm{ac} \text { min }}$ (notice that maximum and minimum values of air cooler and valve in Fig. 4 are selected using the actuator characteristics and limitations in the installation). Energy consumption derived from the use of each one of the manipulated variables has been taken into account when defining the split range controller. A FF controller could be included to compensate for solar-field outlet temperature disturbances, T2.

MD heat exchanger. Two variables must be controlled in the MD heat exchanger: water flow rate, Q3, and inlet temperature, T10. The first one is controlled with the B3 pump speed (frequency percentage), $\mathrm{f}_{\mathrm{B} 3}$, using a PID. In mode 13 , when V5 is fully open and Q2>Q3, T10 2 T4 and the inlet temperature can be controlled with the split range controller described previously. Nevertheless, the additional use of a specific controller in valve V5 could be considered to speed the settling time in setpoint transitions or even to improve the setpoint tracking. For these reasons, a PI controller with a FF term is proposed. The scheme is shown in Fig. 5. The FF is applied to compensate disturbances in the temperature coming from the distribution system, T8. This FF is designed from the static energy balance equation in valve V5:

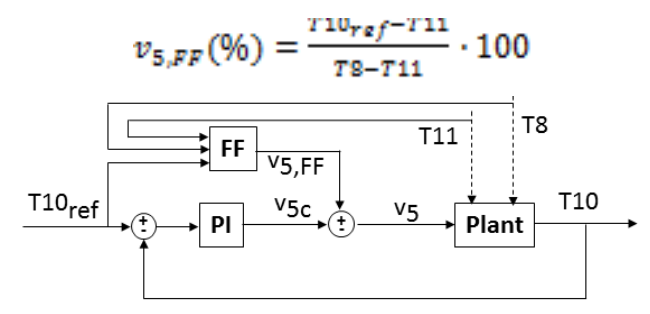

Figure 5. MD heat exchanger temperature control.

Multivariable approaches with decoupling will be also evaluated in view of the preliminary results obtained.

TABLE II. NOMENCLATURE

\begin{tabular}{|lll|}
\hline Variable & Description & Units \\
\hline$c_{f}$ & Conversion factor to account for number of & $9-2-6-10^{4}$ \\
& modules, connections and conversion $1 / \mathrm{min}$ & \\
$c_{5}$ & Specific thermal capacity & 4190 \\
$\mathrm{f}$ & Input frequency & $\mathrm{J} / \mathrm{kg} /{ }^{\circ} \mathrm{C}$ \\
$\mathrm{H}$ & Global thermal losses coefficient & $\%$ \\
$\mathrm{I}$ & Global irradiance & $4.7 \mathrm{~J} / \mathrm{s} / \mathrm{K}$ \\
$\mathrm{n}_{\mathrm{g}}$ & Number of series-connections & $\mathrm{W} / \mathrm{m}^{2}$ \\
$L_{m}$ & Collector absorber tube length & 5 \\
$\mathrm{Q} 1$ & Solar-field water flow rate & $1.95 \mathrm{~m}$ \\
$\mathrm{Q} 2$ & Tank-distribution system water flow rate & $1 / \mathrm{min}$ \\
$\mathrm{Q} 3$ & MD heat exchanger water flow rate & $1 / \mathrm{min}$ \\
$T_{m}$ & Ambient temperature & $1 / \mathrm{min}$ \\
$\mathrm{T} 1$ & Inlet solar-field temperature & ${ }^{\circ} \mathrm{C}$ \\
$\mathrm{T} 2$ & Outlet solar-field temperature & ${ }^{\circ} \mathrm{C}$ \\
$\mathrm{T} 4$ & Water mixture temperature between the & ${ }^{\circ} \mathrm{C}$ \\
& ${ }^{\circ} \mathrm{C}$ \\
$\mathrm{T} 8$ & output of the air cooler and solar field & \\
\hline
\end{tabular}




\begin{tabular}{|c|c|c|c|}
\hline Variable & \multicolumn{2}{|l|}{ Description } & Units \\
\hline T10 & \multicolumn{2}{|c|}{ Inlet heat exchanger temperature } & ${ }^{\circ} \mathrm{C}$ \\
\hline T11 & \multicolumn{2}{|c|}{ Outlet heat exchanger temperature } & ${ }^{\circ} \mathrm{C}$ \\
\hline $\mathrm{u}_{\mathrm{m}}$ & \multicolumn{2}{|c|}{ Split range control input } & - \\
\hline $\mathrm{v}_{1}$ & \multicolumn{2}{|c|}{ Air cooler valve aperture } & $\%$ \\
\hline$\beta$ & \multicolumn{2}{|c|}{ Irradiance model parameter } & $0.123 \mathrm{~m}$ \\
\hline p & \multicolumn{2}{|c|}{ Water density } & $975 \mathrm{~kg} / \mathrm{m}^{2}$ \\
\hline Subscript & Description & Subscript & Description \\
\hline $\begin{array}{l}\mathrm{ac} \\
\mathrm{B} 1\end{array}$ & $\begin{array}{l}\text { Air cooler } \\
\text { Solar-field pump }\end{array}$ & B3 & $\begin{array}{l}\text { MD heat exchanger } \\
\text { pump }\end{array}$ \\
\hline B2 & $\begin{array}{l}\text { Tank-distribution } \\
\text { system pump }\end{array}$ & $\begin{array}{l}\mathrm{C} \\
\mathrm{FF} \\
\text { ref }\end{array}$ & $\begin{array}{l}\text { Feedback control } \\
\text { Feedforward } \\
\text { Setpoint }\end{array}$ \\
\hline
\end{tabular}

\section{RESUlts}

In what follows, preliminary results obtained in two of the described control loops will be shown, as well as results obtained under manual operation.

\section{A. Manual operation}

The operation routine in manual mode is always the same. When the global irradiance is between 600 and $700 \mathrm{~W} / \mathrm{m}^{2}$, the solar field is exposed to it and pump B1 is activated. The position of the three-way valves is I for valves V1 and V2 and II for valves V3 and V4. At the beginning, it is possible to operate with valve V2 in position II to heat the solar field faster, then the position of the valve V2 is changed to I to heat the rest of the circuit. When the input temperature T8 is $10{ }^{\circ} \mathrm{C}$ above the desired temperature in the module, pump $\mathrm{B} 3$ is activated and temperature $\mathrm{T} 1$ decreases considerably because the return of the module is still cold and waiting is necessary. As global irradiance increases, heat provided by the solar field is enough or higher for MD operation. Therefore, the use of an air cooler to dissipate part of this heat is required. This regulation is provided by varying the flow of water that passes through the valve (V1) and the speed of the air cooler. In manual operation, the use of the storage tank is limited to cloudy days or if the water inside is heated to have an energy buffer.

Figures 6 and 7 show the results of one of the experiments carried out with the solar field coupled directly to the MD module without using the thermal storage (operating modes 9 and 13). The experiment starts when heat is introduced in the MD module through the heat exchanger. The experiment lasts $255 \mathrm{~min}$ and the purpose is to test the productivity of the MD module when the hot temperature (T15) is varied between 60 and $75^{\circ} \mathrm{C}$, with steps of $5{ }^{\circ} \mathrm{C}$. Each temperature is kept during $40 \mathrm{~min}$ (except $75{ }^{\circ} \mathrm{C}$ due to weather conditions). The local time for each setpoint is: $60{ }^{\circ} \mathrm{C}: 12: 02$ to $12: 42 ; 65^{\circ} \mathrm{C}: 12: 55$ to $13: 35 ; 70{ }^{\circ} \mathrm{C}: 13: 50$ to $14: 32 ; 75$ ${ }^{\circ} \mathrm{C}: 14: 45$ to $15: 05$. The feed flow rate inside the module (Q10) is around $8.3 \mathrm{l} / \mathrm{min}$. To deliver enough thermal power to the MD system and to avoid working with a too high temperature in the solar field, the flow rate used in the heat exchanger (Q3) is the same (as in this case) or higher than that in the MD module. However, to maximize heat provided by the solar field with the existing radiation the day of the experiment, flow rate Q1 is the highest possible, around 20 $1 /$ min. For the same water flow rates Q3 and Q10, the difference between T10 and T15 is around $8.5{ }^{\circ} \mathrm{C}$. So, to control T15 in the desired temperature it is necessary to keep T10 $8.5{ }^{\circ} \mathrm{C}$ above T15. For that, the air cooler is used in which the flow rate passing through it is controlled thanks to a three-way valve and the power of the air cooler. When the $\%$ valve is below $30 \%$, the effect of the air cooler is insignificant. In this experiment, it was decided to work with a maximum $\%$ valve of $60 \%$ and the power of the air cooler is gradually increased in each tested temperature. At the beginning, the air cooler doesn't work and T2 and T4 are the same. When the air cooler is turned on, since the \% valve used during the experiment is not so high, the effect in the temperature decrease (T4) is not as pronounced, around 2.5 and $3{ }^{\circ} \mathrm{C}$, although the power of the air cooler is high. As observed, with this manual control, it is possible to reach the desired temperature and, as commented in Section III, due to the sensors locations, there is no significate difference between T4 and T10 in operating modes 9 and 13 .

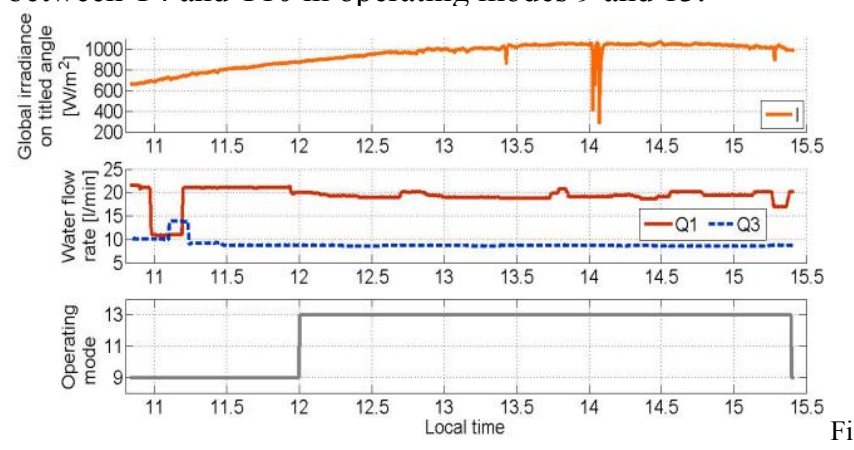

gure 6. Manual control. Irradiance, water flow rate and operating mode.
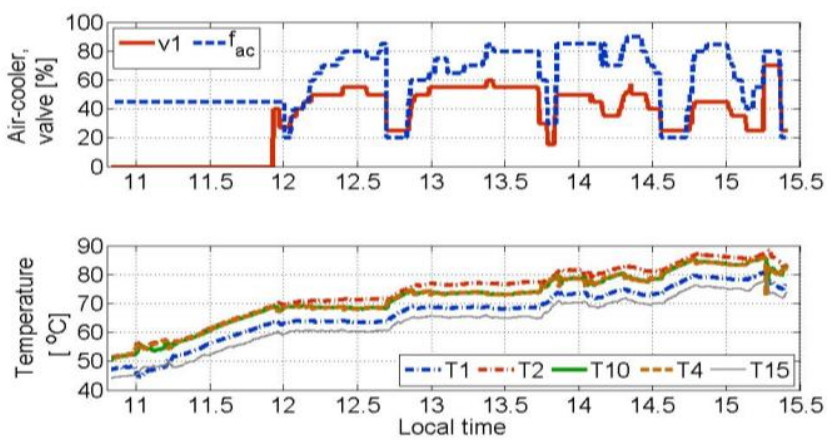

Figure 7. Manual control. Valve V1 aperture, air cooler frequency and temperatures.

\section{B. Automatic control}

In order to obtain basic transfer functions describing the dynamical behavior of the system around the defined operating points, typical step-response tests were performed in all control actuators while trying to keep boundary conditions constant (other controller inputs and disturbances). This was a time consuming task were tests were performed around the solar midday or covering the solar field to avoid transients due to passing clouds. Low-order models were obtained for all subsystems describing the operating modes in Table I. With these basic transfer functions, non-interactive PI and PID control schemes were used.

Solar field. The cascade controller has been configured with the following parameters:

- slave PI controller: $\mathrm{K}_{\mathrm{p}}=2.84 \mathrm{~min} / 1 \cdot \%$ and $\mathrm{T}_{\mathrm{i}}=0.082 \mathrm{~min}$, - outer PI controller: $\mathrm{K}_{\mathrm{p}}=-0.42{ }^{\circ} \mathrm{C} \cdot \mathrm{l} / \mathrm{min}$ and $\mathrm{T}_{\mathrm{i}}=1.21 \mathrm{~min}$.

In this test, the low pass filter in the reference has a time constant of $60 \mathrm{~s}$. Water flow rate is limited between 7.5-19 $1 /$ min, these limits being the maximum and minimum water flow that B1 is able to supply. 
Fig. 8 shows the results of a control test in the solar field. First, the outlet solar field temperature, T2, is controlled in manual mode until reaching $65{ }^{\circ} \mathrm{C}$. In this point, cascade control loop is switched on at time 11:00. When T2 is in steady state, at time $11: 10$, the setpoint is changed to $70^{\circ} \mathrm{C}$. Water flow decreases and T2 reaches the desidered temperature with a steady state error less than $0.2{ }^{\circ} \mathrm{C}$. The time spent in this change is $6.1 \mathrm{~min}$. At time $11: 20$, FF is activated and, at time 11:25, the setpoint decreases to $68^{\circ} \mathrm{C}$. In this case, the steady state error is $0.4{ }^{\circ} \mathrm{C}$ with a settling time of $4.6 \mathrm{~min}$. Also, there is an overshoot of $20 \%$ produced by the FF (due to its static nature and unmodeled dynamics). Then, at time 11:42 the setpoint is increased up to $70{ }^{\circ} \mathrm{C}$. In this step, the steady state error is around $0.3{ }^{\circ} \mathrm{C}$, the settling time is $4 \mathrm{~min}$ and the overshoot is around $20 \%$.

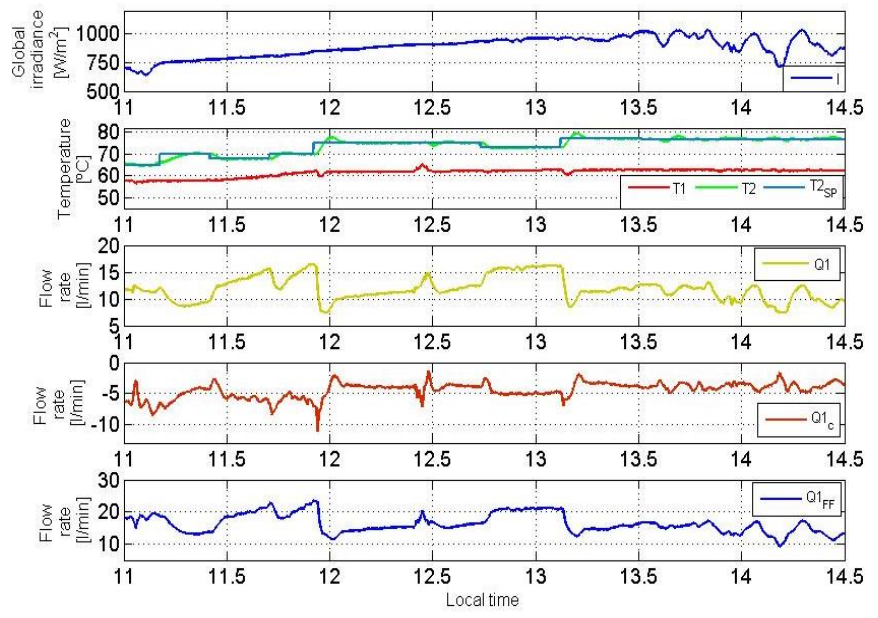

Figure 8. Solar field control. Irradiance, temperatures, flow rate, feedback and feedforward control signals.

At time $11: 55$, the setpoint is changed to $75^{\circ} \mathrm{C}$, the steady state error is less than $0.15^{\circ} \mathrm{C}$, overshoot is $25 \%$ and settling time around $7 \mathrm{~min}$. The settling time increase is due to a disturbance produced by inlet solar field temperature T1 due to recirculation. At time 12:22, there is another disturbance caused by $\mathrm{T} 1$ which is compensated by the FF. There are other two changes in the setpoint at times 12:44 and 13:07 with similar results as in the previus cases. At the end of the experiment, passing clouds produce irradiance oscillations that are in part compensated by the FF block (Fig. 8), which requires feedback due inherent unmodelled dynamics (FF works with filtered values of disturbances).

As a result of this test, there are two issues that must be improved. The first one is to reduce the settling time; outer PI configuration parameters and reference filter should be tuned to improve this time. The second one is to reduce the overshoot by improving both the FF term (reducing unmodeled dynamics and possibly adding some dynamics) and reference filter, trying to find a good tradeoff between setpoint tracking and disturbance rejection.

MD heat exchanger temperature and flow control loops. The following proportional, integral and derivative parameters were obtained:

- temperature PI controller: $\mathrm{K}_{\mathrm{p}}=2.22 \% /{ }^{\circ} \mathrm{C}$ and $\mathrm{T}_{\mathrm{i}}=0.5 \mathrm{~min}$,

- water flow PID controller: $\mathrm{K}_{\mathrm{p}}=5.93 \% \cdot \mathrm{min} / \mathrm{l}, \mathrm{T}_{\mathrm{i}}=0.124 \mathrm{~min}$ and $\mathrm{T}_{\mathrm{d}}=0.024 \mathrm{~min}$.
Valve V5 aperture is limited between $50 \%$ and $80 \%$. The maximum value has been chosen from open loop tests; higher apertures do not affect the water flow rate and the minimum value is considered to assure enough flow in the hydraulic circuit between the MD system and the distribution system avoiding non-desirable shutdowns in pump B3.

Fig. 9 shows the temperature and water flow rate control loops. Initially, V5 valve and B3 pump are controlled in manual mode $\left(\mathrm{v}_{5}=57 \%, \mathrm{f}_{\mathrm{B} 3}=66 \%\right)$. At time 11:30, temperature and flow rate control loops are activated $\left(\mathrm{T} 8_{\text {ref }}=63^{\circ} \mathrm{C}, \mathrm{Q} 3_{\text {ref }}=101 / \mathrm{min}\right)$. Once both controllers are in steady state, Q3 setpoint is changed to $11 \mathrm{l} / \mathrm{min}$. The steady state error is around 0.3 and the settling time is $1.1 \mathrm{~min}$. After that, T8 setpoint is increased up to $66^{\circ} \mathrm{C}$ with a settling time of $3 \mathrm{~min}$, a steady state error around $0.4^{\circ} \mathrm{C}$ and an overshoot of $20 \%$. Then, there is another change in the Q3 setpoint (to $10 \mathrm{l} / \mathrm{min}$ ) with a similar result than the one obtained in the previous step.

At time $12: 10$, setpoint decreases to $63{ }^{\circ} \mathrm{C}$. In this case, the settling time is $7.8 \mathrm{~min}$ due to the fact that valve $\mathrm{V} 5$ is saturated to the minimum which has been set to $50 \%$, T10 is the mean temperature between $\mathrm{T} 8$ and $\mathrm{T} 11$ and therefore, the hot source (T8) limits the system cooling. The cold source used to decrease the temperature is the output of the heat exchanger (T11) which cannot be manipulated and whose dynamics depend on the controlled variable (T10).

At time $12: 25$ setpoint changes to $67^{\circ} \mathrm{C}$ with a settling time of $4.2 \mathrm{~min}$, a steady state error around $0.4{ }^{\circ} \mathrm{C}$ and an overshoot of 25\%. At times 12:50, 13:05, 13:20 there are more positive and negative steps in the setpoint obtaining similar results; overshoot around $25 \%$ and settling time 4 $\min$.

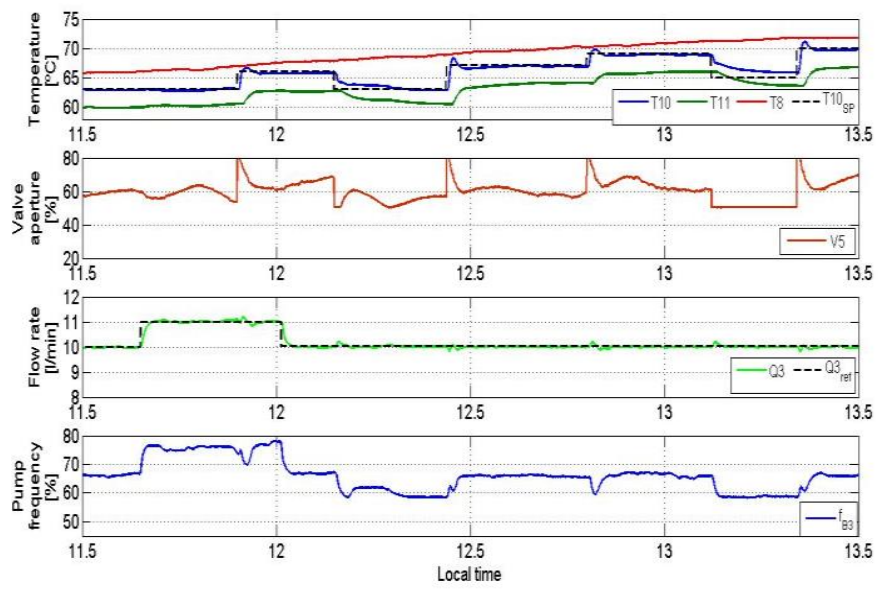

Figure 9. MD heat exchanger and water flow control loops.

From these first results, two main issues must be solved or improved in the temperature control. The first one is to reduce the settling time for negative steps; V5 minimum limit should be reviewed and a more aggressive PI tuning can be chosen for negative setpoint steps. The second one is to reduce the overshoots for positive steps tuning the temperature PI controller or adding a setpoint filter as the one proposed for the solar field controller. 


\section{PRELIMINARY CONCLUSIONS}

Control of SMD units present control challenges. Up to now, the water temperature at the inlet of the heat exchanger, T10, has been controlled in manual mode using mainly the operating modes 9 and 13. Experimental results in section IV.A demonstrate the viability of using the air cooler to reach and maintain the desired temperatures when the solar field water flow rate is saturated at its maximum. Nevertheless, some drawbacks are found using this manual operating strategy: i) air cooler could be used in excess, V1 aperture and air cooler speed should be controlled jointly to reduce the use of non-renewable energy, ii) settling times are in the range between 11 and 24 minutes, iii) irradiance disturbances cause fluctuations in the temperature setpoint of $\pm 2{ }^{\circ} \mathrm{C}$ and iv) part of the thermal power provided by the solar field is wasted using the cooler circuit.

With the preliminary study and first experimental results described in section IV.B looking for a complete automation of this SMD distillate facility, the following main conclusions can be drawn:

- It is possible to use different operating strategies than those used up to now, reaching the desired steady state conditions while keeping the system environmental friendly.

- The test in the solar field shows that settling time can be reduced. With manual control, the solar field is heated using high or maximum flow rates. The desired temperature conditions can be reached early applying a temperature control and also irradiance can be considered explicitly in feedforward actions to avoid temperature variations when non-desirable disturbances occur.

- First experimental results in MD heat exchanger show that valve V5 can be regulated to maintain the desired temperature conditions at the inlet of the heat exchanger, while the water flow rate in this hydraulic circuit is also controlled.

- Settling times could be considerably reduced by $50-70$ $\%$. In solar field test, settling time in the manual operation is around 18 minutes, while with the control loop and feedforward is 7 minutes, more than $50 \%$.

- The use of a specific split range control in the cooler circuit will help to use moderately the air cooler.

Future works will focus on implementing and testing the other control loops and to evaluate alternatives for on-line change of operating modes defined in Table I (through switching or hybrid control approaches). These basic lowlevel control loops will be then integrated within a hierarchical control framework aimed at maximizing the desalination plant efficiency in terms of daily production of distillate while minimizing operating costs through the use of solar energy under varying operating conditions [20].

\section{REFERENCES}

[1] C. Charcosset. "A review of membrane processes and renewable energies for desalination". Desalination, vol. 245, pp. 214-231, 2009.

[2] L.M. Camacho, L. Dumée, J. Zhang, J. Li, M. Duke, J. Gomez and S. Gray. "Advances in membrane distillation for water desalination and purification applications". Water, vol. 5, pp 94-196, 2013.

[3] J.R. Qtaishat and F. Banat. "Desalination by solar powered membrane distillation systems". Desalination, vol. 308, pp. 186-197, 2013.
[4] A. Alkhudhiri, N. Darwish and N. Hilal. Membrane distillation: "A comprehensive review". Desalination, vol. 287, pp. 2-18, 2012.

[5] E. Drioli, A. Ali, and F. Macenonio. "Membrane distillation: Recent developments and perspectives". Desalination, vol. 356, pp. 56-84, 2015.

[6] P. Wang and T.S. Chung. "Recent advances in membrane distillation processes: Membrane development, configuration design and application exploring". J Membr Sci, vol. 474, pp. 39-56, 2015.

[7] E. Guillén-Burrieza, J. Blanco, G. Zaragoza, D.C. Alarcón, P. Palenzuela, M. Ibarra and W. Gernjak." Experimental analysis of an air gap membrane distillation solar desalination pilot system". Journal of Membrane Science, vol. 379, pp. 386-396, 2011.

[8] E. Guillén-Burrieza, G. Zaragoza, S. Miralles-Cuevas, J. Blanco. "Experimental evaluation of two pilot-scale membrane distillation modules used for solar desalination". J Membr Sci, vol. 409-410, pp. 264-275, 2012.

[9] M.S. El-Bourawi, Z. Ding, R. Ma, and M. Khayet. "A framework for better understanding membrane distillation separation process". $J$ Membr Sci, vol. 85, pp. 4-29, 2006.

[10] M. Khayet. "Solar desalination by membrane distillation: Dispersion in energy consumption analysis and water production costs (a review)". Desalination, vol. 308, pp. 89-101, 2013.

[11] G. Zaragoza, A. Ruiz-Aguirre and E. Guillén-Burrieza. "Efficiency in the use of solar thermal energy of small membrane desalination systems for decentralized water production". Appl Energ, vol. 130, pp. 491-499, 2014.

[12] R.S. Saffarini, E.K. Summers, H.A. Arafat and J.H. Lienhard. "Technical evaluation of stand-alone solar powered membrane distillation systems". Desalination, vol. 286, pp. 332-341, 2012.

[13] F. Eleiwi and T.M. Laleg-Kirati. "Dynamic modeling and optimization in membrane distillation system". $19^{\text {th }}$ World IFAC World Congress, Cape Town, South Africa, 2014.

[14] A.S. Nafey, M.A. Sharaf, L. García-Rodríguez. "A new visual library for design and simulation of solar desalination systems". Desalination, vol. 259, pp. 197-207, 2010.

[15] S.B. Abdallah, N. Frikha and S. Gabsi. "Simulation of solar vacuum membrane distillation unit". Desalination, vol. 324, pp. 87-92, 2013.

[16] H. Chang, G-B. Wang, Y-H. Chen, C-C. Li and C-L. Chang. "Modeling and optimization of a solar driven membrane distillation desalination system". Renew Energ, vol. 35, pp. 2714-2722, 2010.

[17] Chang, H., Lyu S-G., Tsai C-M., Chen, Y-H., Cheng, T-W. \& Chou, Y-H. (2012). "Experimental and simulation study of a solar thermal driven membrane distillation desalination process". Desalination, 286, 400-411.

[18] V.A. Bui, L.T.T. Vu and M.H. Nguyen. "Simulation and optimization of direct contact membrane distillation for energy efficiency". Desalination, vol. 259, pp. 29-37, 2010.

[19] A. Vijay, K.V. Ling and A.G. Fane. "Applications of convex optimization in plant-wide control of membrane distillation bioreactor water recycling plant". $11^{\text {th }}$ International Conference on Control, Automation, Robotics and Vision. Singapore, 2010.

[20] J.S. Ling, H. Chang and G.B. Wang. "Modelling and control of the solar powered membrane distillation system". In AIChE annual meeting, Minneapolis, MN, USA, 2011.

[21] R. Porrazzo, A. Cipollina, M. Galluzzo and G. Micale. "A neural network-based optimizing control system for a seawater-desalination solar-powered membrane distillation unit”. Comput Chem Eng, vol. 54, pp. 79-96, 2013.

[22] E.F. Camacho, M. Berenguel, F.R. Rubio and D. Martínez. Control of Solar Energy Systems, Springer, London, 2012.

[23] L. Roca, M. Berenguel, L.J. Yebra and D.C. Alarcón-Padilla. "Solar field control for desalination plants". Sol Energ, vol. 82, pp. 772-786, 2008.

[24] C.O. Ayala, L. Roca, J.L. Guzmán, J.E. Normey-Rico, M. Berenguel and L.J. Yebra. "Local model predictive controller in a solar desalination plant collector field". Renew Energ, vol. 36, pp. 30013012, 2011.

[25] L. Roca, J.L. Guzmán, J.E. Normey-Rico, M. Berenguel and L.J. Yebra. "Robust constrained predictive feedback linearization controller of a collector field of a solar desalination plant". Control Eng Pract, vol. 17, pp. 1076-1088, 2009.

[26] A.Ruiz-Aguirre, D.C Alarcón-Padilla, G.Zaragoza. "Productivity analysis of two spiral-wound membrane distillation prototypes coupled with solar energy". Des Wat Treat, in press, 2015. DOI: 10.1080/19443994.2014.946711. 